\title{
Mental disorders and atopic dermatitis in children and adolescents
}

\author{
Mariana Muzzolon, Sandra Regina Baggio Muzzolon, Mônica Lima, Mariana Canato, Vânia Oliveira Carvalho
}

Pediatric Department, Federal University of Paraná (UFPR), Curitiba, Brazil

Adv Dermatol Allergol 2021; XXXVIII (6): 1099-1104

DOI: https://doi.org/10.5114/ada.2021.112280

\begin{abstract}
Introduction: Some authors point to a relationship between mental disorders (MD) and atopic dermatitis (AD), but few determine which MD these are, and none of them evaluate the impact of $A D$ on their healthy siblings.

Aim: To determine which MD affect children and adolescents with $A D$ and compare it with the risk of their healthy siblings.

Material and methods: This is a cross-sectional, prospective study with the application of a risk assessment instrument for Mental Disorders in paediatric patients with AD and their siblings from September 2016 to June 2018. The evaluation instrument used to assess the risk of MD was the Child Behaviour Checklist (CBCL). The WilcoxonMann-Whitney, Pearson's $\chi^{2}$ test with Yates correction and Fisher's exact test were used, considering a significance level of $5 \%$.

Results: The risk of MD in participants with AD was $63.0 \%$, and in the healthy siblings, $36.0 \%(p<0.01)$. The risk was higher in participants with AD when compared to their siblings for the syndromes "Sleep Problems", "Thought Problems" and "Somatic Complaints". Parental concerns on socialization/bullying were also more frequent for participants with AD when compared to siblings.

Conclusions: Children and adolescents with $A D$ present a high risk of MD, and their healthy siblings also present impairment in their mental health. In both cases, this impairment is higher than the one expected in the Brazilian general paediatric population (24.6\%) and global paediatric population (22.4\%).
\end{abstract}

Key words: atopic eczema, mental disorders, child and adolescents.

\section{Introduction}

Atopic dermatitis (AD) is a cutaneous, inflammatory, chronic, and relapsed disease, characterized by pruritus and eczematous lesions. Clinical manifestations range from mild and localized forms to severe and disseminated ones [1]. The prevalence of AD has steadily increased, affecting $7.9 \%$ of children between 6 and 7 years old and $7.3 \%$ of adolescents between 13 and 14 years old around the world [2].

The pathophysiology of AD includes the interaction of genetic, environmental and immunological factors, and in more than $50 \%$ of the cases, it is associated with other chronic diseases, such as asthma and allergic rhinitis [3]. Among the factors that trigger AD exacerbations, emotional stress is highlighted [4].

The symptoms of AD affect the quality of life (QoL) of patients and their families, mainly due to intense pruritus, unaesthetic appearance of lesions, sleep disturbanc- es, and treatment expenses. Mental health of children and adolescents with AD has been studied in several countries, and it has already been observed that dermatosis contributes to the development of mental disorders (MD) $[1,5,6]$. In Spain, a total of 80 children with AD were evaluated using the instrument "Early Childhood Inventory-4" (ECl-4), and 69\% of them were identified with some MD [6]. In the US, data obtained from telephone interviews on the health of 92,642 children with and without the AD diagnosis showed that children with $A D$ have a higher prevalence of depressive disorder, anxiety disorder, behavioural disorder, autistic spectrum disorder and attention deficit/hyperactivity disorder (ADHD) when compared to their peers who were not affected by the disease [5]. In Brazil, the evaluation of 26 children with AD showed a risk of MD of $78 \%$ [7].

Studies indicate that siblings of children and adolescents with chronic diseases have an impairment in their

Address for correspondence: Mariana Muzzolon, Pediatric Department, Federal University of Paraná (UFPR), Curitiba, Brazil, phone: +55 (41) 99787-8616, e-mail: muzzolon.mariana@gmail.com Received: 26.06.2020, accepted: 3.08.2020. 
mental health. The risk for them is up to three times greater than for the general population regarding behavioural and psychological problems [8, 9]. However, no publications on the evaluation of mental health of healthy siblings of children and adolescents with AD have been found so far.

The high risk of MD in the paediatric age group demands health professionals to use techniques to identify the need for evaluation and treatment of mental health. One alternative for the professionals to improve their skills in identification and, consequently, to enable the early referral of children and/or adolescents with indications of MD is the use of validated scales. The Child Behaviour Checklist ( $\mathrm{CBCL})$ is an example of these scales [10]. It is a large questionnaire considered to be the gold standard. It is supposed to be answered by parents and/ or guardians, based on routine activities and family and social relationships, in order to provide an analysis of the emotional, social and behavioural profile of the child and/or adolescent.

\section{Aim}

The current study aimed to determine the risk of MD in children and adolescents with $A D$ and to compare it with the risk of $M D$ in their respective healthy siblings.

\section{Material and methods}

This study was cross-sectional research aimed to evaluate the risk of MD in children and adolescents with $A D$ and their respective healthy siblings through prospec-

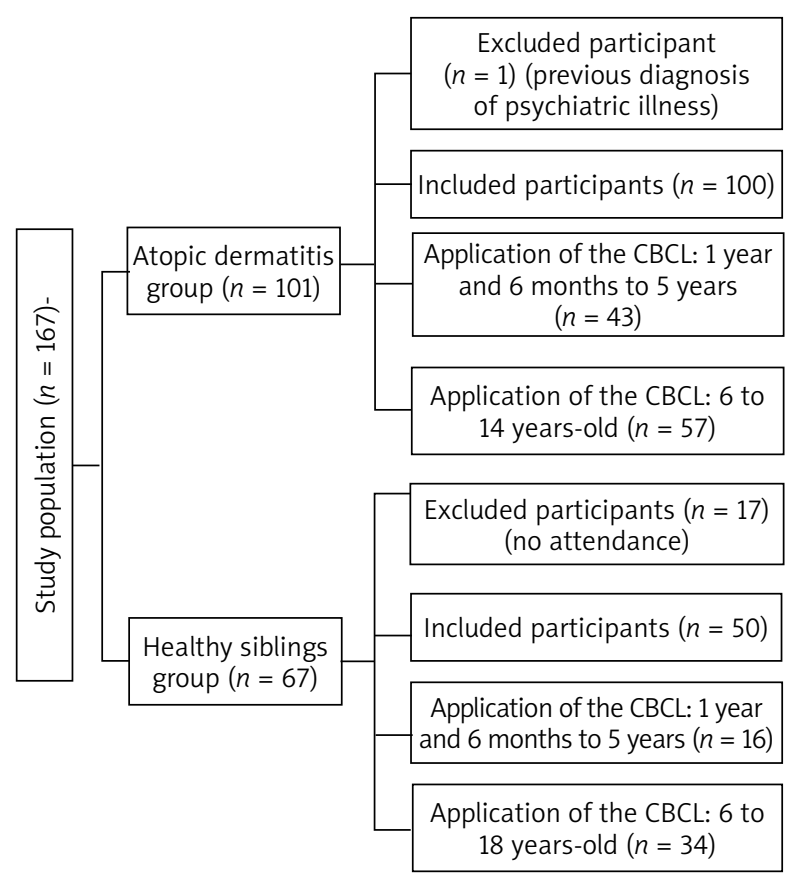

Figure 1. Organization chart on the study and sample population tive data collection. A non-probabilistic, convenience and systematic sample was used to select the participants.

\section{Participants and measures}

All children and adolescents who fulfilled the clinical criteria for AD (atopic dermatitis group - ADG) according to the classification of Hanifin and Rajka [11] were selected. They were seen on two afternoons per week in a tertiary-level hospital. To evaluate the other group (healthy siblings group - HSG), healthy siblings with no clinical diagnosis of AD and other serious chronic diseases were included. Children and adolescents with a previous diagnosis of MD and in follow-up for psychiatric illness were excluded (Figure 1).

The risk of MD was determined using the instrument CBCL (validated for the Portuguese language) [10]. The $\mathrm{CBCL}$ in two versions (pre-school - between 18 months to 5 years/school - between 6 years and 18 years) is indicated to evaluate children and adolescents. It is answered by parents and/or guardians. The version used to evaluate children between the age of 18 months and 5 years contains specific themes for the pre-school age group, being composed of 100 questions that evaluate the following syndromes: "Emotional Reactivity”, "Anxiety/Depression", "Isolation" and "Somatic Complaints", which constitute internalizing problems when grouped together. "Attention Problems" and "Aggressive Behaviour" are grouped as externalizing problems. The syndrome "Sleep Problems" is evaluated separately. The version used to evaluate students between the age of 6 years to 18 years is composed of 113 questions classified in eight syndromes: "Anxiety/Depression", "Isolation" and "Somatic Complaints", grouped as internalizing problems; "Rule-Breaking Behaviour" and "Aggressive Behaviour", grouped as externalizing problems. The syndromes "Social Problems", "Thought Problems" and "Attention Problems" are evaluated separately.

The CBCL consists of questions that should be answered as "absent/not true" (score =0), "sometimes/ slightly true" (score = 1 ) or "often true" (score = 2). At the end, it contains open-ended questions for parents. The sum of scores is converted into T-scores according to analyses that are appropriate for each sex and age. T-score below 64 is Normal; between 65 and 69, Borderline; and equal to or above 70, Clinical.

\section{Ethical approval}

The research was approved by the Committee for Ethics in Research with Human Beings of the University. In all cases, it has received the consent and assent of the participants of the study. No incentives were used.

\section{Statistical analysis}

Wilcoxon-Mann-Whitney test, Pearson's $\chi^{2}$ test with Yates correction and Fisher's exact test were used, considering a significance level of $5 \%$. 


\section{Results}

A total of 150 children and adolescents -100 with a clinical diagnosis of AD (ADG) and 50 healthy siblings (HSG) - participated in the study. The sample of parents and/or guardians who answered the evaluation instruments was composed of 83 (83.0\%) mothers, 9 (9.0\%) fathers and $8(8.0 \%)$ grandparents.

The ADG was composed of 45 (45.0\%) male and 55 (55.0\%) female participants, with median age of 6 years and 6 months (ranging from 1 year and 6 months to 14 years). The presence of risk of at least one MD classified by the CBCL was observed in $63.0 \%$ of this group. Internalizing problems were observed in $42.0 \%$ of the cases, and externalizing problems, in $30.0 \%$.

The HSG was composed of 30 (60.0\%) male and 20 (40.0\%) female participants, with median age of 8 years and 5 months (ranging from 1 year and 7 months to 17 yearsold and 5 months). The presence of risk of at least one MD classified by the CBCL was observed in $36.0 \%$ of this group. Internalizing problems occurred in $24.0 \%$ of the cases and externalizing problems, in 22.0\% (Figure 2).

Regarding CBCL syndromes in the ADG, "Sleep Problems", "Thought Problems" and "Anxiety/Depression" were the most frequent ones. In the HSG, the most frequent syndromes were "Rule-Breaking Behaviour", "Thought Problems" and "Aggressive Behaviour" (Table 1).

Comparing the groups, except for "Rule-Breaking Behaviour", there was a higher frequency in the ADG for all CBCL syndromes, when compared to the HSG, especially for "Somatic Complaints", "Sleep Problems" and "Thought Problems" (Table 1). The risk of "Sleep Problems" was twice as high in the ADG participants as in the SG $(R R=2.86$; 95\% Cl: 1.18-6.92).

Answers to CBCL's open-ended question "What are your biggest concerns regarding your child?" were categorized and presented in Table 2 . With regards to parental con-

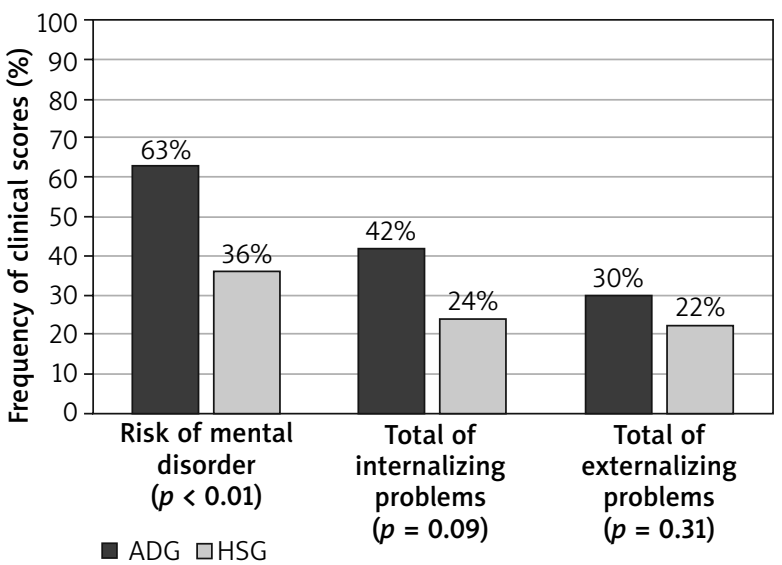

Figure 2. Risk of mental disorders, total internalizing problems and total externalizing problems, according to the child behaviour checklist (CBCL) in the atopic dermatitis group (GDA) and the healthy siblings group (HSG). Pearson's $\chi^{2}$ test with Yates correction

cerns of the ADG, symptoms related to the disease, such as pruritus, appearance of lesions, chronicity and treatment expenses, were the most frequent mentions. The second concern was related to socialization/bullying problems (including physical and verbal abuse and social exclusion). Lastly, parents mentioned concern related to low academic performance. Regarding the HSG, the main concerns were related to low academic performance, followed by minor illnesses, and socialization/bullying problems.

\section{Discussion}

The risk of MD was higher in children and adolescents with $A D(63.0 \%)$ than in their healthy siblings (36.0\%), and higher than the estimates for the general Brazilian

Table 1. Frequency of syndromes classified as clinical according to the Child Behaviour Checklist (CBCL) in the Atopic Dermatitis Group (ADG) and the Healthy Siblings Group (HSG)

\begin{tabular}{|c|c|c|c|}
\hline Syndromes in CBCL & $\begin{array}{l}\text { ADG } \\
n(\%)\end{array}$ & $\begin{array}{l}\text { HSG } \\
n(\%)\end{array}$ & $P$-value \\
\hline Emotional Reactivity & $6(14.0)^{1}$ & $1(6.3)^{4}$ & $0.66^{8}$ \\
\hline Anxiety/Depression & $25(25.0)^{2}$ & $9(18.0)^{5}$ & $0.60^{7}$ \\
\hline Isolation & $16(16.0)^{2}$ & $5(10.0)^{5}$ & $0.60^{7}$ \\
\hline Somatic Complaints & $16(16.0)^{2}$ & $2(4.0)^{5}$ & $0.03^{8}$ \\
\hline Sleep Problems & $26(60.5)^{1}$ & $2(12.5)^{4}$ & $<0.01^{8}$ \\
\hline Attention Problems & $20(20.0)^{2}$ & $5(10.0)^{5}$ & $0.29^{7}$ \\
\hline Aggressive Behaviour & $20(20.0)^{2}$ & $10(20.0)^{5}$ & $0.62^{7}$ \\
\hline Social Problems & $18(31.6)^{3}$ & $6(17.6)^{6}$ & $0.19^{7}$ \\
\hline Thought Problems & $28(49.1)^{3}$ & $7(20.6)^{6}$ & $0.01^{7}$ \\
\hline Rule-Breaking Behaviour & $11(19.3)^{3}$ & $9(26.5)^{6}$ & $0.44^{8}$ \\
\hline
\end{tabular}

${ }^{1} n=43 ;{ }^{2} n=100 ;{ }^{3} n=57 ;{ }^{4} n=16 ;{ }^{5} n=50 ;{ }^{6} n=34 ;{ }^{7}$ Pearson's $\chi^{2}$ test with Yates correction; ${ }^{8}$ Fisher's exact test 
Table 2. Frequency of responses to the open-ended question of the child behaviour checklist $(\mathrm{CBCL})$ "What are your biggest concerns regarding your child?", in the atopic dermatitis group (ADG) and the healthy siblings group (HSG)

\begin{tabular}{|c|c|c|c|}
\hline $\begin{array}{l}\text { CBCL } \\
\text { concerns }\end{array}$ & $\begin{array}{l}\text { ADG } \\
n(\%)\end{array}$ & $\begin{array}{l}\text { HSG } \\
n(\%)\end{array}$ & $P$-value \\
\hline Symptoms of AD (ADG)/Minor Illness (HSG) & $46(46.0)^{1}$ & $5(10.0)^{2}$ & $<0.001^{3}$ \\
\hline Socialization/Bullying & $33(33.0)^{1}$ & $2(4.0)^{2}$ & $<0.001^{4}$ \\
\hline Academic Performance & $15(15.0)^{1}$ & $12(24.0)^{2}$ & $0.17^{3}$ \\
\hline
\end{tabular}

${ }^{1} n=100 ;{ }^{2} n=50 ;{ }^{3}$ Pearson's $\chi^{2}$ test with Yates correction; ${ }^{4}$ Fisher's exact test.

population (24.6\%) [12]. These data are corroborated in the literature, suggesting that AD may contribute to the development of MD [1,5-7]. These results are similar to those found by Catal et al. [6] who measured through the Early Childhood Inventory-4 (ECl-4) that 69\% of the children with AD had at least one psychiatric diagnosis.

Amongst the syndromes evaluated, "Sleep Problems" was the most observed syndrome $(60.5 \%)$ in the ADG. Similar results were found in other studies, such as the research by Ridolo et al. [13] which evaluated sleep-related problems in $62.3 \%$ of the children with AD through the Pittsburgh Sleep Quality Index (PSQI). The frequency observed in this study is similar to that noted in the study by Chamlin et al. [14] who assessed the presence of sleep disorders in $60 \%$ of the paediatric patients with $A D$, and Fishbein et al. [15], who identified sleep problems in 60\% of the children and adolescents with AD. These two results were obtained by means of the Children's Dermatology Life Quality Index (CDLQI).

The second most frequent syndrome was "Thought Problems", observed in $49.1 \%$ of the ADG. According to parents, their children have presented persistent thoughts due to their concern about the disease and its effects. Most of them have stated that their children frequently manipulate parts of their body and remove scaling skin or eczema. The high frequency of the syndrome "Thought Problems" in the paediatric population with AD was found in the literature by a study that used $C B C L$ to evaluate 25 children diagnosed with AD and 25 controls. The children in the group with $A D$ were more concerned and rigid in their thoughts in comparison to the controls $(32.0 \%$ vs. $4.0 \%$ ) [16]. In the present study, it was found that the complexity of details in the daily management of the disease as well as the lack of emotional strategies of the child and/or adolescent to deal with $\mathrm{AD}$ lead to the repetition of thoughts and acts that characterize this syndrome.

The third most frequent syndrome in the ADG was "Anxiety/Depression", observed in $25 \%$ of the cases. Similar results were found in a study by Slattery et al. [17], who diagnosed Anxiety Disorder in $26 \%$ of the paediatric population with AD through the Schedule for Affective Disorders and Schizophrenia for School-Age Children Present and Lifetime version (K-SADS-PL). In a study by Catal et al. [6], who evaluated 80 children with $A D$, the frequency of anxiety was $13 \%$. The divergence of these studies may result from the use of different instruments (CBCL, K-SADS-PL and ECl-4), as well as the different age groups evaluated (1 year and 6 months - 14 years, 13-17 years, and 3-5 years, respectively). Another difference among the studies is that this study used risk criteria for MD and the two studies used diagnostic criteria.

In the present research, 33\% of the ADG cases reported that children and/or adolescents suffered physical/ verbal violence (bullying). In 31.6\% of the cases, "Social Problems" were observed, and in $16 \%$, signs of "Isolation" were observed. These signs are mainly identified by statements, in which they affirm that they prefer being alone rather than with others, being reserved, and keeping their thoughts and feelings to themselves. These results are in accordance with studies that affirm that children and adolescents with AD suffer social isolation and peer rejection [17-19]. Thus, conviviality and management of $A D$ may interfere with the emotional and social development of the children and/or adolescents and their family members.

Siblings of children and adolescents with chronic diseases constitute a population at risk for MD. However, since there are no studies on MD in siblings of children and adolescents with AD so far, the literature used in this study was based on siblings of children and adolescents with other chronic diseases [20-23]. In the present study, the risk of MD was found in $36.0 \%$ in the HSG. A similar frequency was described in a study by Besier et al. [21], in which $30.5 \%$ of the healthy siblings of children with cancer, cystic fibrosis and congenital heart disease presented emotional problems. Williams et al. [9] found that siblings of children with chronic diseases are twice or three times more likely to present emotional problems than the general population. This situation can be explained by the conflict that these children feel concerning their sibling's illness, such as fear (of the illness), jealousy, and rage (due to the special attention given to the ill child by the parents). In this group, the syndrome "Rule-Breaking Behaviour" was the most frequent one (26.5\%), being characterized by behaviours such as breaking rules, lying, and not feeling guilty after showing inappropriate behaviour. Probably because they are in development, healthy siblings may not understand the special needs of the ill sibling and present inappropriate and/or exaggerated behaviours. 
Comparing the ADG and the HSG, the syndrome that presented the highest differences were: "Sleep Problems" (60.5\% vs. $12.5 \%, p<0.01)$ ) "Thought Problems" (49.1\% vs. $20.6 \%, p=0.01)$, and "Somatic Complaints" (16.0\% vs. $4.0 \%, p=0.03)$. Thus, the analysis of the results shows that the chronic and relapsed nature of the skin disease affects the patient. Besides, it enhances data on the risk of MD in healthy siblings of children and adolescents with AD. Such result has not been published in the literature yet.

Children and adolescents - healthy or with chronic diseases - have the same needs during their development. Nonetheless, meeting the needs that are characteristic of each stage of child development and, simultaneously, dealing with stressful factors caused by a chronic disease is more difficult for the ill child [23]. Symptoms and conviviality with the disease may change and even aggravate the mental development of the child and adolescent, as well as interfere in their interaction with the environment.

The present study presented limitations; for instance, data on the participants' behaviour were obtained through a single source of information, in this case, the main parent or guardian who was accompanying the patient during the outpatient visit. It is also necessary to consider the lack of evaluation of the causality of associations, considering the cross-sectional nature of this study. Longitudinal studies may verify the persistence of symptoms, as well as the conditions associated with their attenuation or intensification over time. The use of screening tools by healthcare teams is also recommended to prevent mental healthcare problems.

\section{Conclusions}

Children and adolescents with AD present a high risk of $M D$, greater than the one expected for the general paediatric population. The healthy siblings of these children and adolescents also exhibit impairment in their mental health. However, the frequency of risk factors is lower when compared to their siblings with AD. Nevertheless, this group presents a higher risk than the one expected for the general paediatric population.

\section{Acknowledgments}

The author would like to thank all study participants for completing the survey.

\section{Conflict of interest}

The authors declare no conflict of interest.

\section{References}

1. Schmitt J, Romanos M, Schmitt N, et al. Atopic eczema and attention-deficit/hyperactivity disorder in a population- based sample of children and adolescents. JAMA 2009; 301: 724-6.

2. Mallol J, Crane J, Von Mutius E, et al. The International Study of Asthma and Allergies in Childhood (ISAAC) Phase Three: a global synthesis. Allergol Immunopathol 2013; 41: 73-85.

3. Kapoor R, Menon C, Hoffstad O, et al. The prevalence of atopic triad in children with physician confirmed atopic dermatitis. J Am Acad Dermatol 2008; 58: 68-73.

4. Campos ALB, Araújo FM, Santos MAL, et al. Impacto da dermatite atópica na qualidade de vida de pacientes pediátricos e seus responsáveis. Rev Paul Pediatr 2017; 35: 5-10.

5. Yaghmaie P, Koudelka CW, Simpson EL. Mental health comorbidity in patients with atopic dermatitis. J Allergy Clin Immunol 2013; 131: 428-33.

6. Catal F, Topal E, Soylu N, et al. Psychiatric disorders and symptoms severity in preschool children with atopic eczema. Allergol Immunopathol 2016; 44: 120-4.

7. Dias NG. Avaliação Comportamental de crianças com doenças crônicas de pele a partir de relatos de suas mães [dissertação]. Londrina, PR: Universidade Estadual de Londrina 2010.

8. Taylor V, Fuggle P, Charman T. Well sibling adjustment to chronic physical disorder in a sibling: how important is maternal awareness of their illness attitudes and perceptions? J Child Psychol Psychiatry 2001; 42: 953-62.

9. Williams PD, Williams AR, Graff JC, et al. A Communitybased intervention for siblings and parents of children witch chronic illness or disability: the ISEE study. J Pediatrics 2003; 143: 386-93.

10. Bordin IAS, Mari JJ, Caeiro MF. Validação da versão brasileira do Child Behavior Checklist (CBCL) (Inventário de comportamentos da Infância e Adolescęncia): dados preliminares. Rev ABP-APAL 1995; 17: 55-66.

11. Hanifin JM, Rajka G. Diagnostic features of atopic dermatitis. Acta Derm Venereol Suppl 1980; 92: 44-7.

12. Paula CS, Duarte CS, Bordin IA. Prevalence of mental health problems in children and adolescents from the outskirts of Sao Paulo City: treatment needs and service capacity evaluation. Rev Bras Psiquiatr 2007; 29: 11-7.

13. Ridolo E, Caffarelli C, Olivieri E, et al. Quality of sleep in allergic children and their parents. Allergol Immunopathol 2015; 43: 180-4.

14. Chamlin SL, Frieden IJ, Williams ML, Chren MM. Effects of atopic dermatitis on young American children and their families. Pediatrics 2004; 114: 607-11.

15. Fishbein AB, Mueller K, Kryse L, et al. Sleep disturbance in children with moderate/severe atopic dermatitis: a casecontrol study. J Am Acad Dermatol 2018; 78: 336-41.

16. Fontes Neto PTL, Weber PTL, Fortes MB, et al. Avaliação dos sintomas emocionais e comportamentais em crianças portadoras de dermatite atópica. Rev Psiquiatr Rio Gd Sul 2005; 27: 279-91.

17. Slattery MJ, Essex MJ, Paletz EM, et al. Depression, anxiety, and dermatologic quality of life in adolescents with atopic dermatitis. J Allergy Clin immunol 2011; 128: 668-71.

18. Shin J, Choi Y, Park E, et al. Psychiatry outpatient visits by atopic dermatitis patients varying in the complexity of their prescriptions: a nationwide cohort study conducted from 2005 to 2013. Medicine 2016; 95: e5411.

19. Ballardini N, Kramer MS, Oken E, et al. Associations of atopic dermatitis and asthma with child behaviour: results from the PROBIT cohort. Clin Exp Allergy 2019; 49: 1235-44. 
20. Pedrosa C, Valle E. Artigos da equipe multiprofissional de saúde da criança: ser irmão de criança com câncer: estudo compreensivo. Pediatria 2000; 22: 195-4.

21. Besier T, Hölling H, Schlack R, et al. Impact of a family-oriented rehabilitation programme on behavioural and emotional problems in healthy siblings of chronically. Child Care Helth Dev 2010; 36: 686-95.

22. Dórea A. Efeitos psicológicos em irmãos saudáveis de crianças portadoras de cardiopatias congęnitas [dissertação]. Universidade de São Paulo, São Paulo 2010.

23. Castro EK, Piccinini CA. Implicações da doença orgânica crônica na infância para as relações familiares: algumas questões teóricas. Psicol Reflex Crít 2002; 15: 625-35. 